\title{
Cyclophilin D regulates lifespan and protein expression of aging markers in the brain of mice
}

\author{
Viktoria Vereczki ${ }^{\mathrm{a}}$, Josef Mansour ${ }^{\mathrm{b}, \mathrm{c}}$, Issa Pour-Ghaz ${ }^{\mathrm{b}, \mathrm{c}}$, Ibolya Bodnar ${ }^{\mathrm{d}}$, Otto Pinter ${ }^{\mathrm{e}}$, Dora Zelena ${ }^{\mathrm{e}}$, \\ Erzsebet Oszwald $^{\mathrm{a}}$, Vera Adam-Vizi ${ }^{\mathrm{b}, \mathrm{f}}$, Christos Chinopoulos ${ }^{\mathrm{b}, \mathrm{c}, *}$ \\ a Department of Anatomy, Histology and Embryology, Semmelweis University, Budapest, Hungary \\ ${ }^{\mathrm{b}}$ Department of Medical Biochemistry, Semmelweis University, Budapest, Hungary \\ ${ }^{c}$ MTA-SE Lendület Neurobiochemistry Research Group, Budapest, Hungary \\ d Department of Human Morphology and Developmental Biology, Semmelweis University, Budapest, Hungary \\ e Institute of Experimental Medicine, Hungarian Academy of Sciences, Budapest, Hungary \\ ${ }^{\mathrm{f}}$ MTA-SE Laboratory for Neurobiochemistry, Budapest, Hungary
}

\section{A R T I C L E I N F O}

\section{Article history:}

Received 13 June 2016

Received in revised form 19 January

2017

Accepted 9 March 2017

Available online $\mathrm{xxx}$

Keywords:

GFAP

mGluR1

Alpha-synuclein

Permeability transition

Heterozygote

Mitochondria

\section{A B S T R A C T}

Cyclophilin D (cypD) modulates the properties of the permeability transition pore, a phenomenon implicated in the manifestation of many diseases including aging. Here, we examined the effects of partial or complete deletion of cypD on i) lifespan, ii) forebrain protein expression of 18 aging markers as well as regional expression of GFAP, mGluR1, and alpha-synuclein, and iii) behaviour of aged (> 24 month) male and female mice. Both male and female cypD heterozygous but not KO mice exhibited increased lifespans compared to WT littermates, associated with alterations in the protein expression of some markers, albeit without exhibiting changes in behaviour.

CC 2016 Published by Elsevier Ltd.

\section{Introduction}

Cyclophilin D (cypD) is a mitochondrially localized peptidyl-prolyl cis-trans isomerase (Johnson et al., 1999) and a binding target of the immunosuppressant cyclosporin A (Davis et al., 2010; Halestrap and Davidson, 1990). Both physiological and pathological functions of this protein stem from its isomerase domain (Baines et al., 2005), modulating the mitochondrial permeability transition pore (PTP) (Bernardi et al., 2015a). The PTP is a non-selective high-conductance channel which allows the flux of water and other molecules up to $1500 \mathrm{Da}$ across the inner mitochondrial membrane (Azzolin et al., 2010). The physiological role of cypD and the PTP is to link mitochondrial ATP production with cellular functional demand through $\mathrm{Ca}^{2+}$ (Korge et al., 2011; Barsukova et al., 2011), reviewed in Elrod and Molkentin (2013). The contribution of PTP to pathology has been much more intensely investigated, aided greatly by the availability of cypD knock-out (KO) mice (Baines et al., 2005; Basso et al., 2005; Nakagawa et al., 2005; Schinzel et al., 2005). A vast body of work has led to the understanding that cypD is a critical determinant of a number of pathologies (Bonora et al., 2015), and thus, a drug target (Waldmeier et al., 2003). Indeed, cypD deficient mice

\footnotetext{
* Corresponding author at: Department of Medical Biochemistry, Semmelweis University, Tuzolto Street 37-47, Budapest 1094, Hungary.

Email address: chinopoulos.christos@eok.sote.hu (C. Chinopoulos)
}

overexpressing mutant amyloid precursor protein (mAPP) exhibited less $\mathrm{Ca}^{2+}$-induced mitochondrial swelling, increased mitochondrial $\mathrm{Ca}^{2+}$ uptake capacity, preserved mitochondrial respiratory function and improved spatial learning/memory, even in old age (22-24 months of age) (Du et al., 2011). Accordingly, cypD deficiency attenuated mitochondrial and neuronal perturbation in addition to preserving learning and memory in a mouse model of Alzheimer's disease (Du et al., 2008), examined at 12 months of age. Furthermore, the genetic ablation of cypD delayed disease onset, and extended the lifespan of mutant $\alpha$-synuclein mice (Martin et al., 2014). Importantly, not just in the mAPP overexpressing mice (Du et al., 2008) but also cypD deficiency alone improved spatial learning and memory.

On the other hand, mice lacking cypD exhibited an enhancement of anxiety, avoidance behaviour was facilitated, and adult-onset obesity was prominently evident from the 10 month of age, which was not dependent on increased food and/or water intake (Luvisetto et al., 2008). cypD KO mice also exhibited substantially greater cardiac hypertrophy, fibrosis, and reduction in myocardial function in response to pressure overload stimulation than WT mice (Elrod et al., 2010). Along these lines, CaMKII $\delta$ c overexpression in cypD KO mice resulted in heart failure characterized by a loss of left ventricular function and significant mortality (Elrod et al., 2010). Yet, clinical trials have shown that administration of the cyclophilin D inhibitor, cyclosporin A, was protective to patients immediately after myocardial 
infarction, when applied during the revascularization phase (Piot et al., 2008).

Apart from their contribution to the aetiology of diseases, mitochondria have also been considered to be involved in aging (Crompton, 2004; Toman and Fiskum, 2011). Relevant to this, aging studies in the human and murine brain resulted in the identification of "aging markers" that concern gene expression and DNA damage. Specifically, from post-mortem samples of the frontal pole of 30 individuals ranging in age from 26 to 106, RNA was harvested and analysed using Affymetrix gene chips (Lu et al., 2004) and age-related genes were identified by performing statistical group comparison of frontal cortical samples from individuals $\leq 42$ and $\geq 73$ years old; it was found that about $4 \%$ of the approximately 11,000 genes analysed were significantly changed (1.5-fold or more) (Lu et al., 2004). Likewise, the effects of aging on gene expression in the brain of mice have also been examined (Jiang et al., 2001). Statistically significant differences in gene expression in the hypothalamus and cortex of young ( 2 months old) and aged ( 22 months old) mice have been found by using high-density oligonucleotide arrays, and a number of key genes involved in neuronal structure and signalling were differentially expressed (Jiang et al., 2001). A similar study using oligonucleotide arrays representing 6347 genes determined the gene-expression profile of the aging neocortex and cerebellum in mice (Lee et al., 2000). There, it was found that aging resulted in a gene-expression profile indicative of an inflammatory response, oxidative stress and reduced neurotrophic support in both mouse brain regions (Lee et al., 2000).

Mindful of the connection of cypD to PTP and that of the latter to aging, we examined the contribution of partial or complete deletion of cypD in protein expression of aging markers in the mouse brain. Given that in the human aging brain, gene expression changes are sexually dimorphic (Berchtold et al., 2008), we examined both male and female mice. In the study where human frontal cortex aging markers were sought ( $\mathrm{Lu}$ et al., 2004), 466 genes exhibited very significant alterations. This gene pool was subdivided in 11 "functions", namely, synaptic functions, vesicular transport, neuronal survival, protein turnover, amino acid modification, mitochondrial functions, stress response, inflammation, myelination/lipid metabolism, transcription, and hormonal functions. From these 466 genes, we selected 15 proteins on the basis of four criteria: i) there are well-characterized mouse homologues, ii) they are distributed among most of the 11 subdivided gene pools, iii) they show a large up- or down regulation compared to all members of the 466 genes, and iv) there are verified antibodies available, which are suitable for both Western blotting and immunohistochemistry for the expressed proteins in mice. These proteins were: ATP6V1H, Calbindin, calcineurin B, Cdk5, GFAP, HIF1 $\alpha$, Leptin Receptor, MEK4, mGluR1, PKC- $\gamma$, Synapsin, Sortilin and VAMP1. Additionally, we examined the expression of $\alpha$-synuclein, a marker which is central to disease-progression in Alzheimer's disease as well as MnSOD as a mitochondrial marker. GAPDH and $\beta$-actin were used as house-keeping genes. Some of the above aging markers were further selected for quantitative evaluation of immunohistochemical sections of the motor cortex, hippocampal and thalamic regions of the mice. Finally, in addition to examining protein expression, we also compared the lifespan of the mice groups, and evaluated their behaviour at $>24$ months of age.

\section{Results}

\subsection{The effect of partial or complete deletion of cypD in the lifespan} of male and female mice

As shown in Fig. 1A, the survivals of male WT $(\mathrm{n}=514)$, HT $(\mathrm{n}=147)$ and KO $(\mathrm{n}=644)$, and in panel 1B female WT $(\mathrm{n}=322)$,

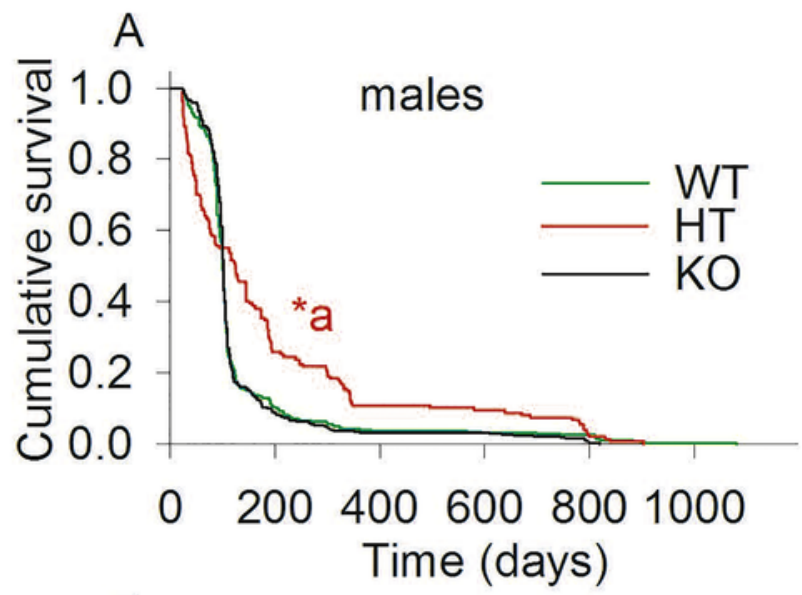

B

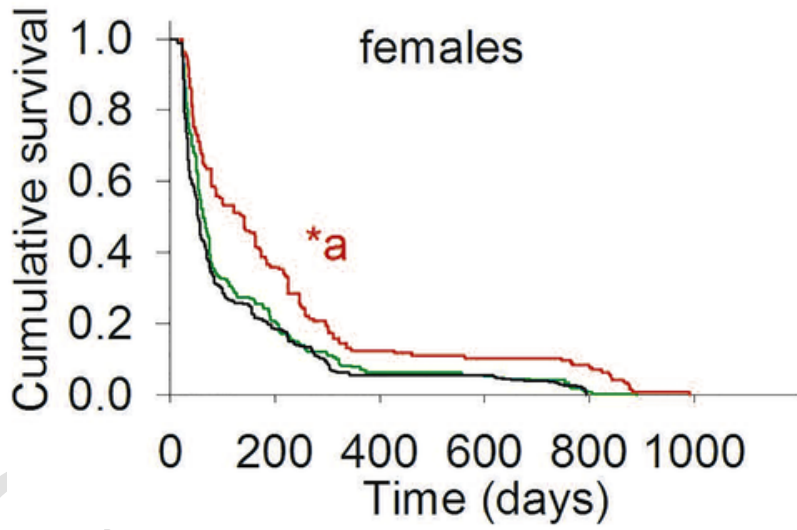

Fig. 1. The effect of partial or complete deletion of cypD in the lifespan of male and female WT, cypD heterozygous and cypD KO mice. Kaplan-Meier plots were calculated from lifetime data of WT (green), HT (red) and KO (black) CypD mice. *a $<0.001$, (HT vs WT or KO, either gender) using a post-hoc with a Holm-Sidak test for pairwise multiple comparison. (For interpretation of the references to color in this figure legend, the reader is referred to the web version of this article.)

HT $(n=145)$ and KO $(n=358)$ were recorded until the time of their natural death, and plotted using Kaplan-Meier analysis. By applying a post-hoc with a Holm-Sidak test for pairwise multiple comparisons, it is apparent that both male and female HT mice exhibited longer lifespan $(\mathrm{p}<0.001)$ than both WT and KO mice. No statistical significant difference was observed between WT and KO mice of either gender. Some of these mice have undergone behavioural evaluation at the age of 24 months (see Section 2.4). Interestingly though, male HT mice exhibited an early lethality compared to KO and WT mice. Gross pathological examination of the deceased mice did not show any major abnormalities, though the exact cause of death was not estimated. The reason(s) for the early lethality of male HT mice was not investigated further.

\subsection{The effect of partial or complete deletion of cypD in the expression of aging markers in the forebrain of mice}

As shown in Fig. 2 for male and Fig. 3 for female, forebrain homogenates from $5 \mathrm{WT}, 5 \mathrm{HT}$ and $5 \mathrm{KO}$ mice (all $>24$ months of age) were probed for the expression of the following proteins: cypD, $\beta$-actin, GAPDH, $\alpha$-synuclein, ATP6V1H, calbindin, calcineurin B, Cdk5, GFAP, HIF1 $\alpha$, leptin receptor, MEK4, mGluR1, MnSOD, PKC- $y$, synapsin, sortilin and VAMP1. On the left side of the figures, scanned images of the Western blots are shown. The densitometric 


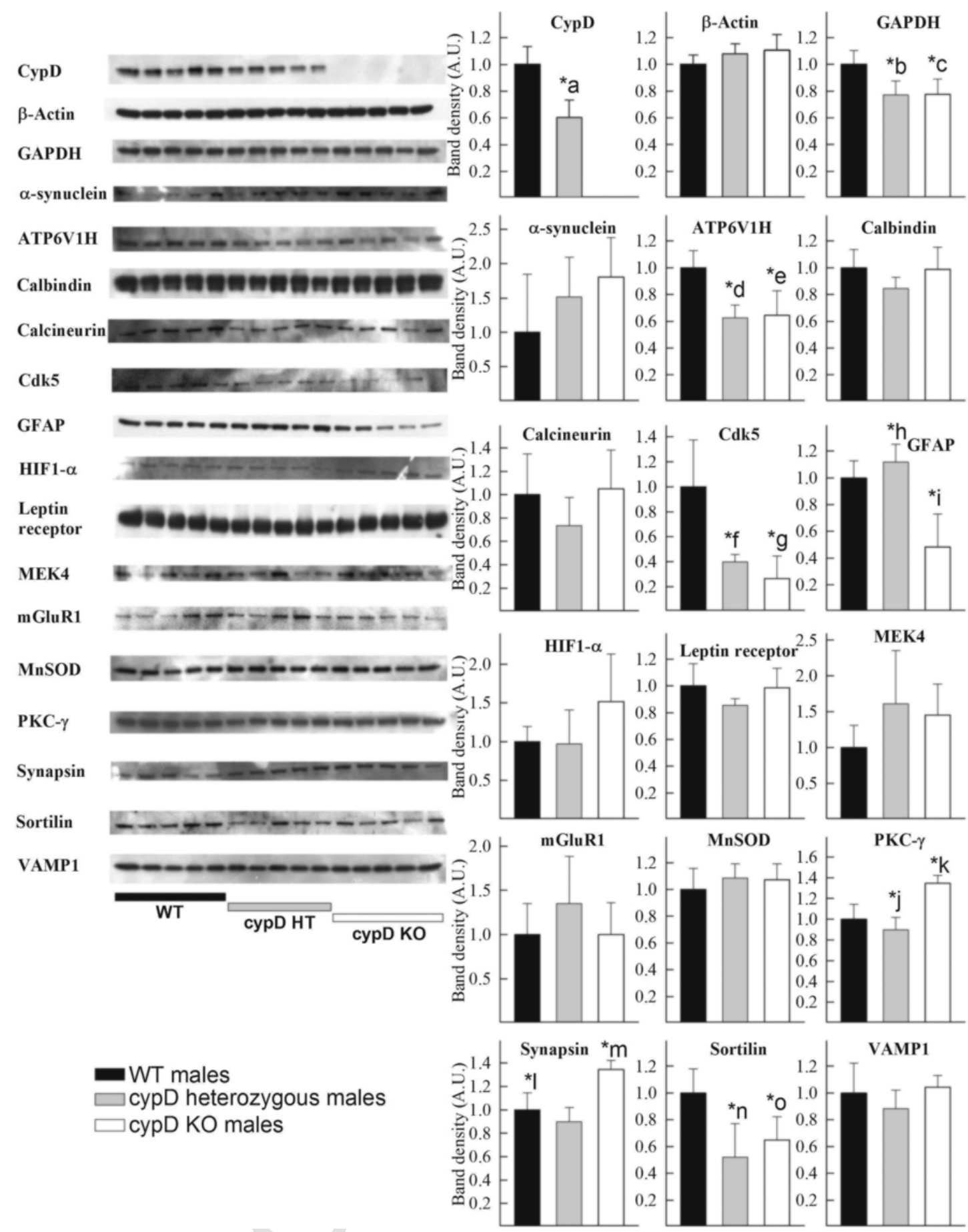

Fig. 2. Left: Scanned images of Western blotting comparing the forebrain homogenates of $5 \mathrm{WT}, 5$ cypD heterozygous and 5 cypD KO male mice (all $>24$ months of age) on aging markers, as indicated in the figure. Right: densitometric analysis of the bands from the Western blotting scans. Statistical significance was determined comparing the 3 groups (WT, HT, KO) by ANOVA on Ranks followed by one-way ANOVA and Tukey's test post-hoc analysis. Data with $\mathrm{p}<0.05$ were considered significant. Graphs are plotted as means with bars representing the standard error of the mean. *a $<0.001$, WT vs HT; *b, *c $=0.008$ WT vs HT, WT vs KO; *d, *e $=0.002$ WT vs HT, WT vs KO; *f, *g $<0.001$ WT vs HT, WT vs $\mathrm{KO} ;{ }^{*} \mathrm{~h}, *_{\mathrm{i}}<0.001$ WT vs KO, HT vs KO; ${ }^{\mathrm{j}}$, *k<0.001, WT vs KO, HT vs KO; ${ }^{*},{ }^{*} \mathrm{~m}<0.001$, WT vs HT, HT vs KO; ${ }^{n}$, * ${ }^{\circ}=0.008$ WT vs HT, WT vs KO.

analysis of the bands (assigning an O.D. of 1 for the averaged bands obtained from the WT mice, black bars) is shown as graphs, plotted as means with bars representing the standard error of the mean, in the panels to the right. Statistical significance was determined comparing the 3 groups (WT, HT, KO) by ANOVA on Ranks followed by one-way ANOVA and Tukey's test post-hoc analysis. Data with $\mathrm{p}<0.05$ were considered significant. All antibodies yielded single cept calbindin which yielded a duplet) at the expected molecular weights. The antibodies used and their titers are shown in Table 1. Statistical significant differences are indicated in the panels. From the panel showing the densitometric analysis of the bands corresponding to cypD, it is evident that HT mice possess $60 \%$ (males) and $53 \%$ (females) of the averaged total cypD amount of the WT mice. As expected, KO mice did not show any cypD immunoreactivity. What is 

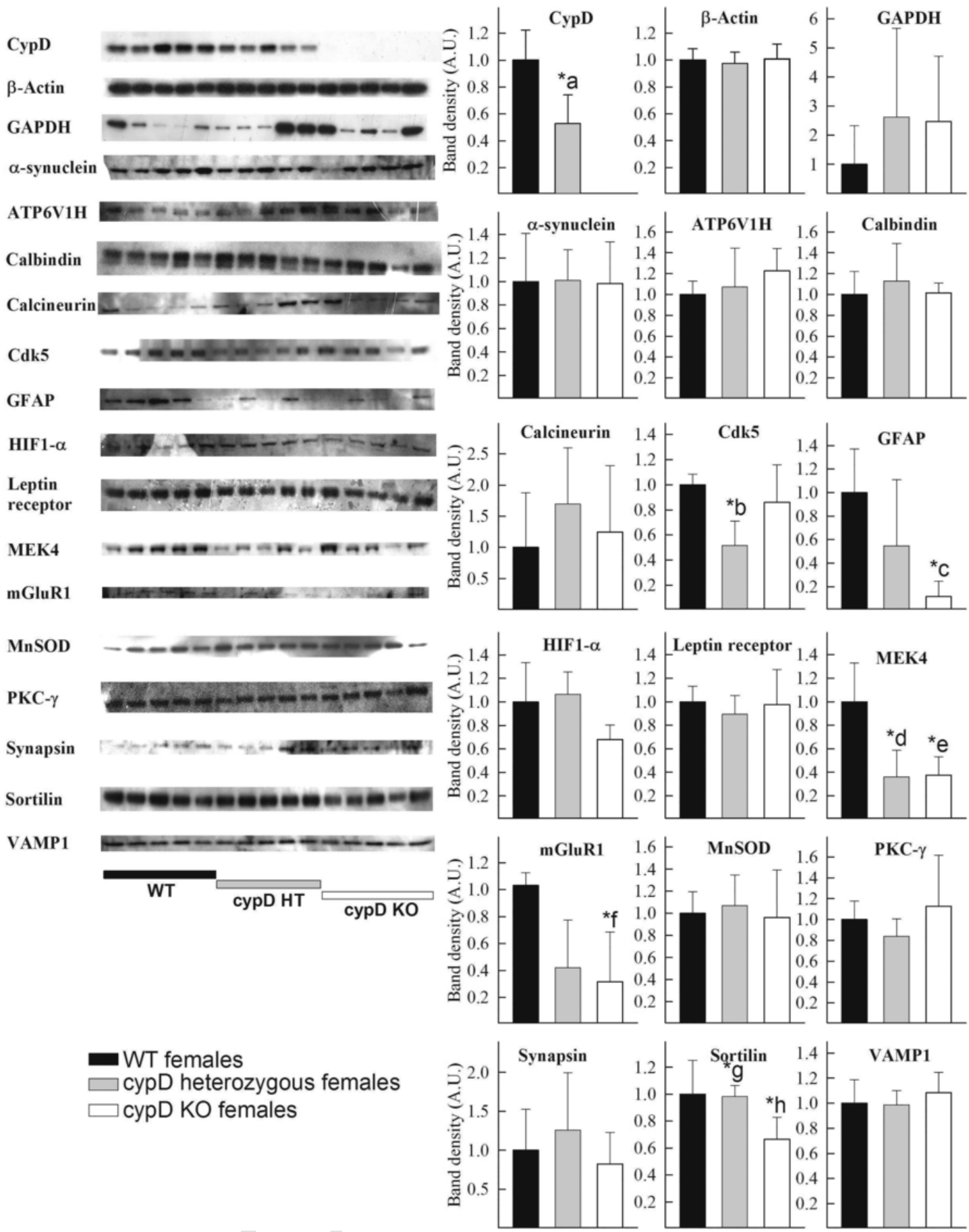

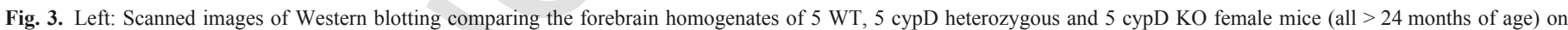

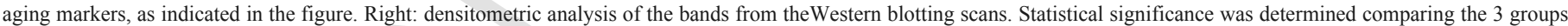

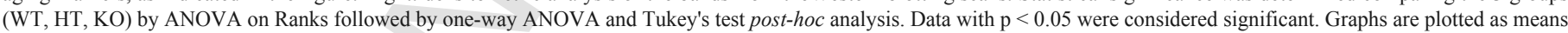

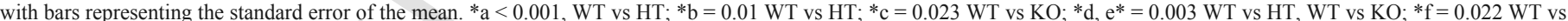
$\mathrm{KO} ;{ }^{*}{ }^{*},{ }^{*} \mathrm{~h}=0.02$, WT vs KO, HT vs KO.

also evident from the GAPDH blots of the female mice is that there is very large variability, unlike the blots for $\beta$-actin. As elaborated under the Materials and methods section, by ratioing the densitometric signal of each band to that obtained using $\beta$-actin we obtained the exact same information regarding statistical comparisons. Thus, bar-graphs representing densitometric analyses of band intensities are given by assigning an O.D. of 1 for the averaged bands obtained from
WT mice. From the aging markers, those that yielded statistically significant differences among the mice groups were: for male mice, GAPDH, ATP6V1H, cdk5, GFAP, PKC- $\gamma$, synapsin and sortilin, and for female mice, cdk5, GFAP, MEK4, mGluR1 and sortilin. In most cases the levels were lower either only in $\mathrm{KO}$ or both in $\mathrm{HT}$ and $\mathrm{KO}$ animals. Only in male KO, PKC- $\gamma$ and synapsin showed elevations in protein expression, which were not detected in HT or any other fe- 
Table 1

Antibodies used for Western blotting, their titers and origin.

\begin{tabular}{lll}
\hline Marker & Titer & Origin \\
\hline Alpha synuclein & $1: 2000$ & ab78155 (Abcam) \\
ATP6V1H & $1: 2000$ & ab96120 (Abcam) \\
Beta-actin & $1: 5000$ & ab6276 (Abcam) \\
Calbindin & $1: 1000$ & ab11426 (Abcam) \\
Calcineurin B & $1: 250$ & ab94535 (Abcam) \\
Cdk5 & $1: 2000$ & ab40773 (Abcam) \\
CypD & $1: 1000$ & MSA04 (Mitosciences) \\
GAPDH & $1: 5000$ & ab8245 (Abcam) \\
GFAP & $1: 4000$ & ab10062 (Abcam) \\
HIF1 alpha & $1: 2000$ & ab1 (Abcam) \\
Leptin receptor & $1: 4000$ & ab5593 (Abcam) \\
MEK4 & $1: 1000$ & ab39403 (Abcam) \\
mGluR1 & $1: 2000$ & gift from Dr. Shigemoto \\
MnSOD & $1: 2000$ & ab13533 (Abcam) \\
PKCy & $1: 1000$ & ab71558 (Abcam) \\
Sortilin & $1: 1000$ & ab16640 (Abcam) \\
Synapsin II & $1: 2000$ & ab76494 (Abcam) \\
VAMP1 & $1: 1000$ & ab3346 (Abcam) \\
\hline
\end{tabular}

male group. A comparison of the changes obtained in our study using Western blotting and that of $\mathrm{Lu}$ et al. (2004) regarding mRNA levels is shown in Table 2.

\subsection{The effect of partial or complete deletion of cypD in the regional expression of GFAP, $m$ GluR1 and $\alpha$-synuclein in the brain of mice}

As shown in Fig. 4A, the CA1 region of an aged male WT, a cypD heterozygous and a cypD KO mouse was decorated for mGluR1 (green), GFAP (red), and the neuronal marker NeuN (blue). Similar stainings were obtained from the brains of female mice (not shown). In the stratum radiatum, mainly GFAP fibers are visible with reduced density in HT and KO animals. mGluR1 immuno-positive fibers are equally present in all three genotypes with more prominent amount in stratum oriens and alveus. In panel 4B, GFAP-decorated parts of the motor cortex and thalamus are shown, using single immunocytochemistry by Ni-DAB intensification; this was performed as such in order to avoid any bleaching of the fluorophores during quantification. Again, for these regions and identical protocols, a similar staining was obtained from the brains of female mice (not shown). From these results it is evident that our staining immunohistochemical protocols yielded specific decoration for the intended proteins, thus affording the necessary assurance for further quantitative evaluation. The results obtained from the quantitative evaluation of GFAP staining for CA1 region, motor cortex and thalamus are shown in Fig. 4 panels $\mathrm{C}-\mathrm{D}, \mathrm{E}-\mathrm{F}$, and $\mathrm{G}-\mathrm{H}$, for male and female mice, respectively. It is noteworthy, that there seems to be more mGluR1 staining in stratum pyramidale (p) of WT mice, in comparison to HT and $\mathrm{KO}$ mice. We did not seek the reason(s) explaining this finding, which would warrant the use of electron microscopy in order to identify precisely the location of the mGLuR1 staining. We speculate that in WT mice the soma of the neurons or perhaps the perisomatic region of the neurons (including the soma, proximal dendrites, initial segments of the axon as well postsynaptic density elements) exhibit more intense mGLuR1 staining compared to HT or cypD KO mice. It would be interesting to address the neuronal network changes of glutamatergic innervation of pyramidal neurons among the 3 mice groups by quantifying the layers of the CA1 region separately using electron microscopy.

The staining for mGluR1 in the motor cortex and thalamus was performed using single immunocytochemistry using Ni-DAB intensification, and a representative IHC micrograph is shown in Fig. 5, for male mice. Similar stainings were obtained from the brains of female mice (not shown). The anti-mGluR1 antibody was validated from the micrographs shown in Figs. 4 and 5, decorating different parts of the pericarya of dendrites. The results obtained from the quantitative evaluation of mGluR1 staining for CA1 region and the motor cortex are shown in Fig. 5, bottom panels for male and female mice. mGluR1 staining in the thalamus was not quantitated due to the very intense staining that emerged from this part of the mouse brain.

The staining for $\alpha$-synuclein in the CA1 region and the following cortical regions: 'EC': entorhinal cortex, 'S': subiculum, and ' $\mathrm{Cg} 2$ ': cingulate gyrus subfield 2 was performed using single immunocytochemistry by Ni-DAB intensification, and a representative IHC micrograph is shown in Fig. 6, for male mice. Similar stainings were obtained from the brains of female mice (not shown). The expression of $\alpha$-synuclein in the thalamus was not investigated, as it has not been associated with any disease exhibiting a direct relation to aging. The results obtained from the quantitative evaluation of $\alpha$-synuclein staining for CA1 and cortical regions are shown in Fig. 6, bottom panels.

\subsection{The effect of partial or complete deletion of cypD on anxiety-related behaviour}

The locomotion-related parameters, namely the number of line crossings on the OF and the closed arm entries on the EPM (Fig. 7) did not show any significant alterations among genotypes and genders, suggesting that the anxiety-related parameters are not influenced by them. However, the anxiety-related measures, the time

Table 2

Comparison of changes in aging markers described in Lu et al. versus this study.

\begin{tabular}{|c|c|c|c|c|c|c|c|}
\hline $\begin{array}{l}\text { Aging } \\
\text { marker }\end{array}$ & $\begin{array}{l}\text { Fold-change in } \\
\text { study by Lu et al. }\end{array}$ & $\begin{array}{l}\text { Change in this study } \\
\text { WT vs HT (males) }\end{array}$ & $\begin{array}{l}\text { Change in this study } \\
\text { WT vs KO (males) }\end{array}$ & $\begin{array}{l}\text { Change in this study } \\
\text { HT vs KO (males) }\end{array}$ & $\begin{array}{l}\text { Change in this study } \\
\text { WT vs HT (females) }\end{array}$ & $\begin{array}{l}\text { Change in this study } \\
\text { WT vs KO (females) }\end{array}$ & $\begin{array}{l}\text { Change in this study } \\
\text { HT vs KO (females) }\end{array}$ \\
\hline$\alpha$-Synuclein & n.d. & n.s. & n.s. & n.s. & n.s. & n.s. & n.s. \\
\hline ATP6V1H & -2.27 & Reduced $(\mathrm{p}=0.003)$ & Reduced $(\mathrm{p}=0.005)$ & n.s. & n.s. & n.s. & n.s. \\
\hline Calbindin & -2.50 & n.s. & n.s. & n.s. & n.s. & n.s. & n.s. \\
\hline Calcineurin & -2.83 & n.s. & n.s. & n.s. & n.s. & n.s. & n.s. \\
\hline Cdk5 & -3.41 & Reduced $(\mathrm{p}=0.006)$ & Reduced $(<0.001)$ & n.s. & Reduced $(\mathrm{p}=0.009)$ & n.s. & n.s. \\
\hline GFAP & 1.61 & n.s. & Reduced $(\mathrm{p}=0.002)$ & Reduced $(<0.001)$ & n.s. & Reduced $(\mathrm{p}=0.019)$ & n.s. \\
\hline HIF $1-\alpha$ & 2.05 & n.s. & n.s. & n.s. & n.s. & n.s. & n.s. \\
\hline $\begin{array}{l}\text { Leptin } \\
\text { receptor }\end{array}$ & 1.69 & n.s. & n.s. & n.s. & n.s. & n.s. & n.s. \\
\hline MEK4 & -3.09 & n.s. & n.s. & n.s. & Reduced $(\mathrm{p}=0.006)$ & Reduced $(\mathrm{p}=0.009)$ & n.s. \\
\hline mGluR1 & -2.41 & n.s. & n.s. & n.s. & n.s. & Reduced $(\mathrm{p}=0.022)$ & n.s. \\
\hline $\mathrm{PKC}-\gamma$ & -1.77 & n.s. & Increased $(p=0.002)$ & Increased $(\mathrm{p}<0.001)$ & n.s. & n.s. & n.s. \\
\hline Synapsin & -3.43 & n.s. & Increased $(p=0.002)$ & Increased $(\mathrm{p}<0.001)$ & n.s. & n.s. & n.s. \\
\hline Sortilin & -3.52 & Reduced $(\mathrm{p}=0.008)$ & Reduced $(\mathrm{p}=0.045)$ & n.s. & n.s. & Reduced $(\mathrm{p}=0.030)$ & Reduced $(\mathrm{p}=0.039)$ \\
\hline VAMP1 & -3.42 & n.s. & n.s. & n.s. & n.s. & n.s. & n.s. \\
\hline
\end{tabular}



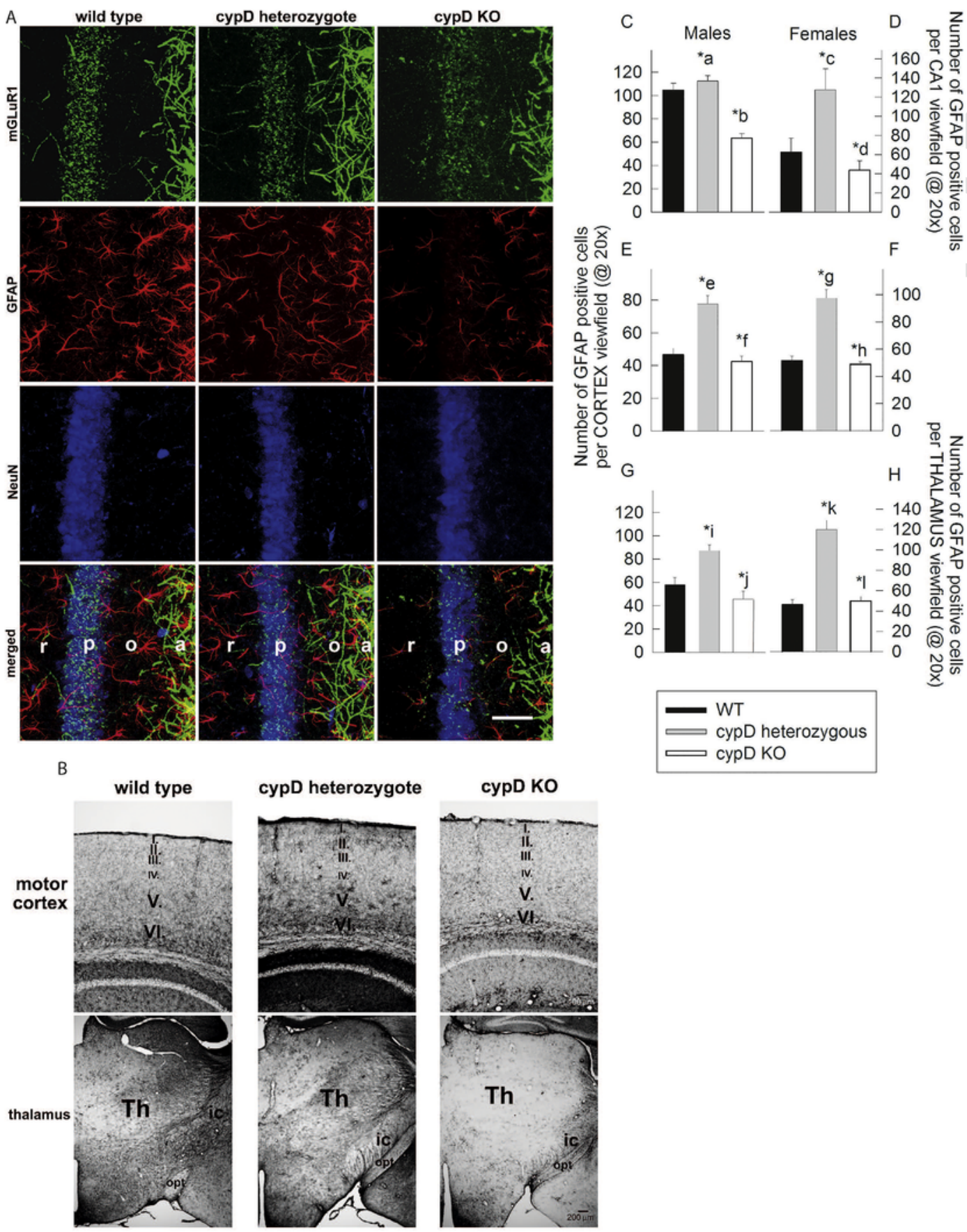

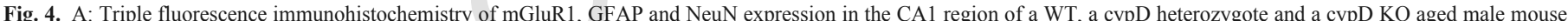

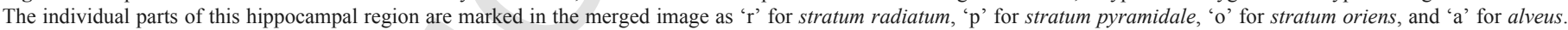

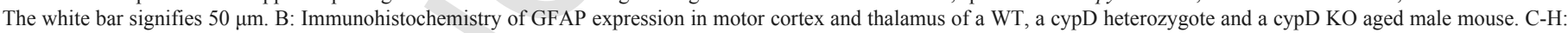

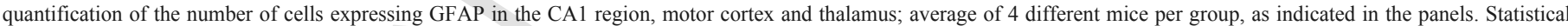

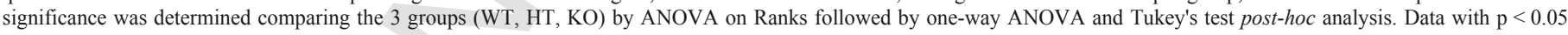

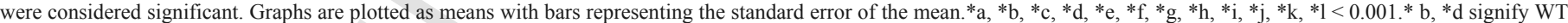
vs KO. All other, HT vs KO. (For interpretation of the references to color in this figure, the reader is referred to the web version of this article.)

spent in the centrum of the OF, and the time spend on the open arm of the EPM was also independent from the genotype and gender.

\section{Discussion}

Mitochondrial dysfunction is increasingly recognized to be intricately associated with cellular senescence and the overall aging of an organism, often in ways extending beyond the well-known mechanisms of oxidative stress and bioenergetic deficits (Yin et al., 2016; Lane et al., 2015; Payne and Chinnery, 2015; Gonzalez-Freire et al., 2015; Ziegler et al., 2015). More recently, the 'causality-status' of this association has been challenged in light of findings suggesting that age-dependent mitochondrial dysfunction is not only insufficient to limit life span, but some of the biochemical manifestations of mi- 


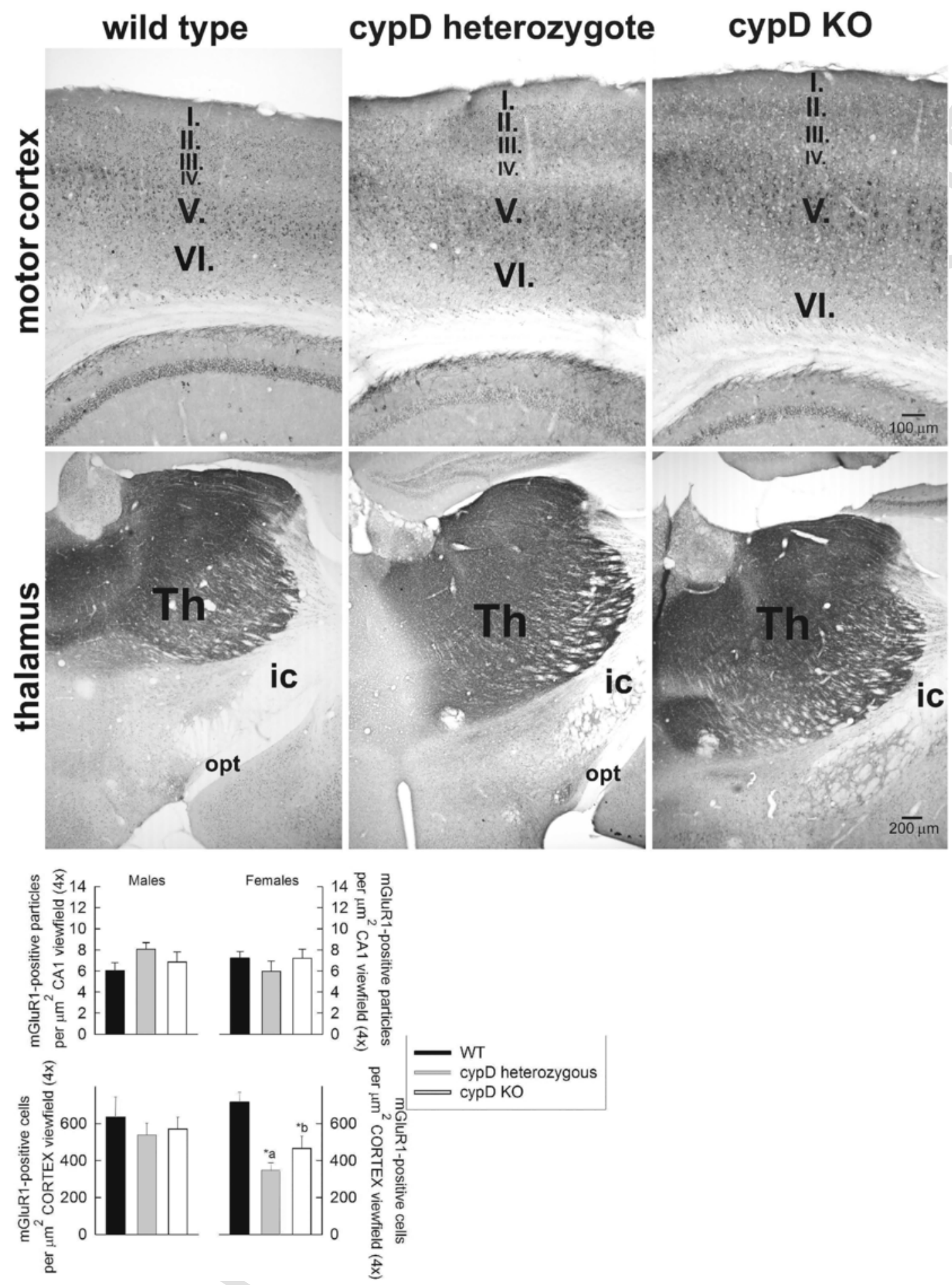

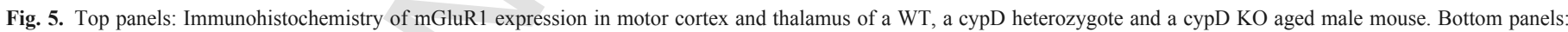

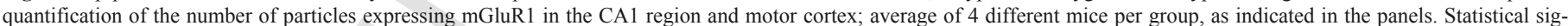

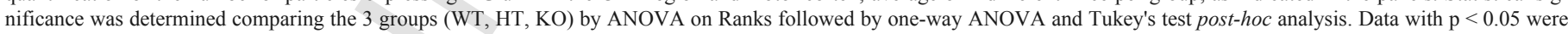
considered significant. Graphs are plotted as means with bars representing the standard error of the mean. ${ }^{*} \mathrm{a},{ }^{*} \mathrm{~b}<0.001$

tochondrial stress can even stimulate pro-longevity pathways (Wang and Hekimi, 2015; Gonzalez-Freire et al., 2015; Yin et al., 2016). In either case, all studies agree that mitochondrial dysfunction plays a complex role in regulating cellular and organismal aging.

Mitochondrial dysfunction usually leads to a common final pathway substantiated by the opening of the PTP (Izzo et al., 2016).
Opening of the PTP has been mostly associated with ominous signs for the cell, such as inducing necrotic pathways (Bernardi et al., 2015b). However, cypD-mediated PTP is also associated with physiological events (Laker et al., 2016). Nonetheless, cypD is recognized as a dispensable, but modulatory component of this pore-opening mechanism (Bernardi et al., 2015b; Bonora et al., 2015). In the pre- 


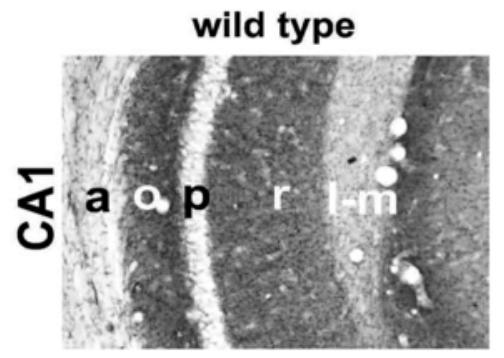

cypD heterozygote
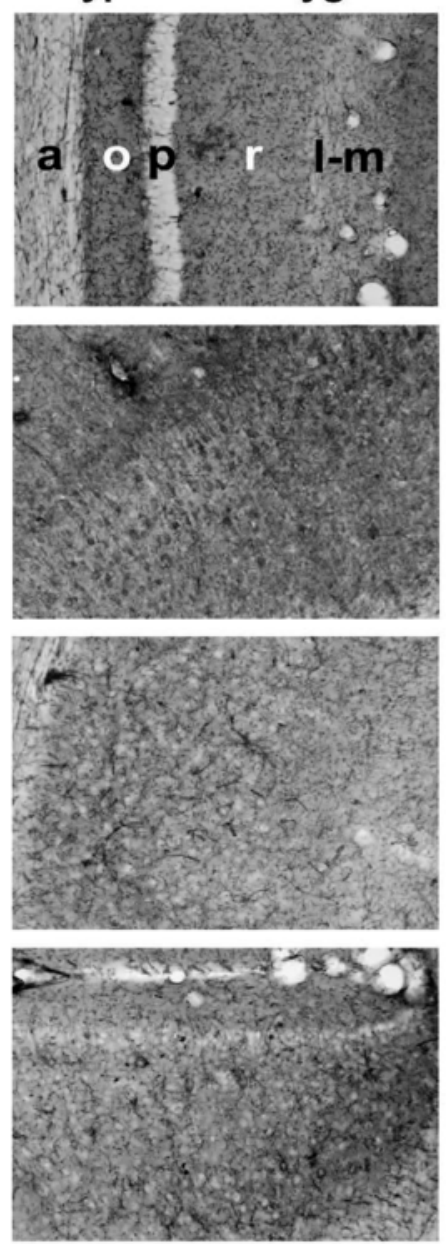
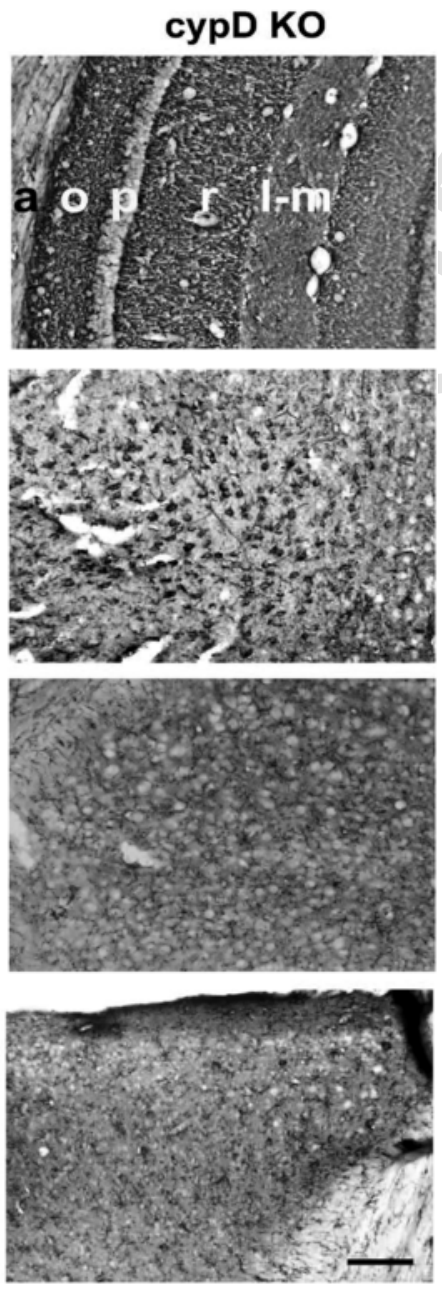

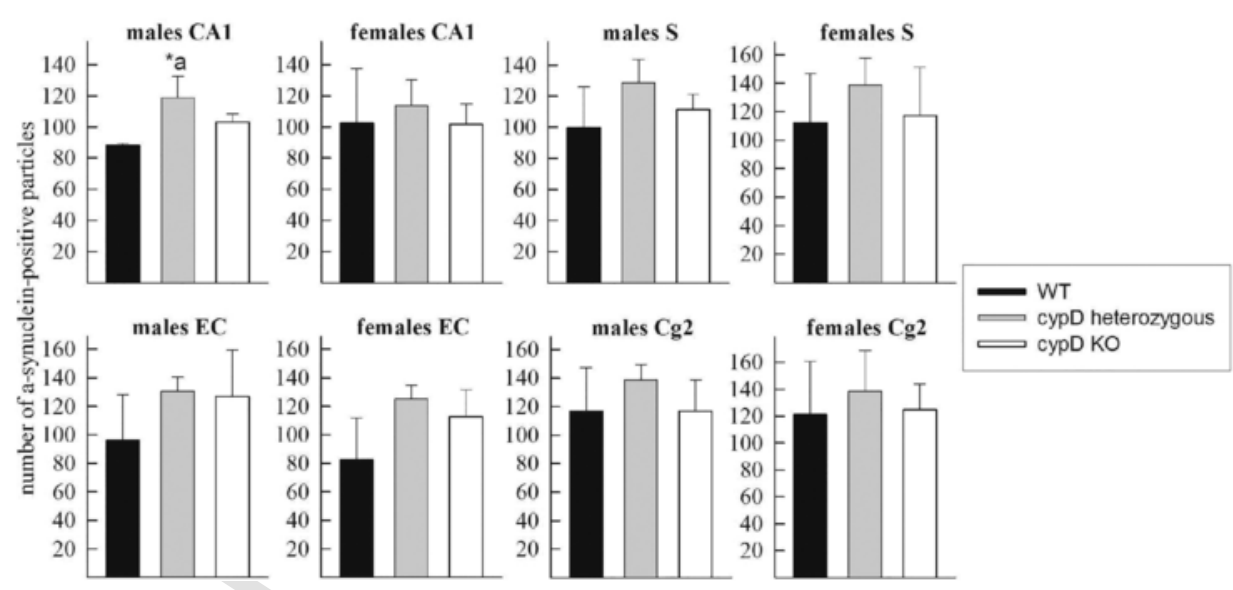

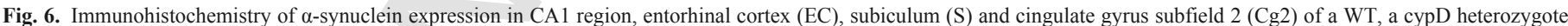

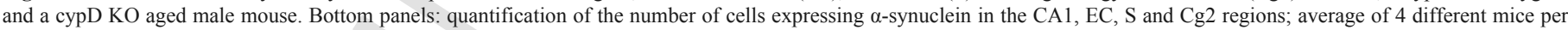

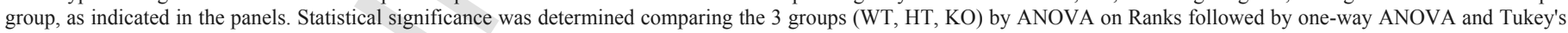
test post-hoc analysis. Data with $\mathrm{p}<0.05$ were considered significant. Graphs are plotted as means with bars representing the standard error of the mean. *a $=0.002$.

sent work we examined the effects of partial or complete deletion of cypD on i) lifespan, ii) protein expression of aging markers in whole forebrain as well as regional expression of GFAP, mGluR1 and $\alpha$-synuclein and iii) behaviour of aged (> 24 month) male and female transgenic mice. The rationale of including cypD heterozygous mice in the study was based on the fact that -to the best of our knowledge- the overwhelming majority of all other studies using transgenic mice compared the effects of complete cypD deletion versus WT. However, Wang et al. (2009) did evaluate the contribution of cypD to hypoxic-ischemic injury in WT, HT and KO mice and Eliseev et al. (2007) the age-dependent level of expression of cypD as a function of $\mathrm{Ca}^{2+}$-induced PTP. 

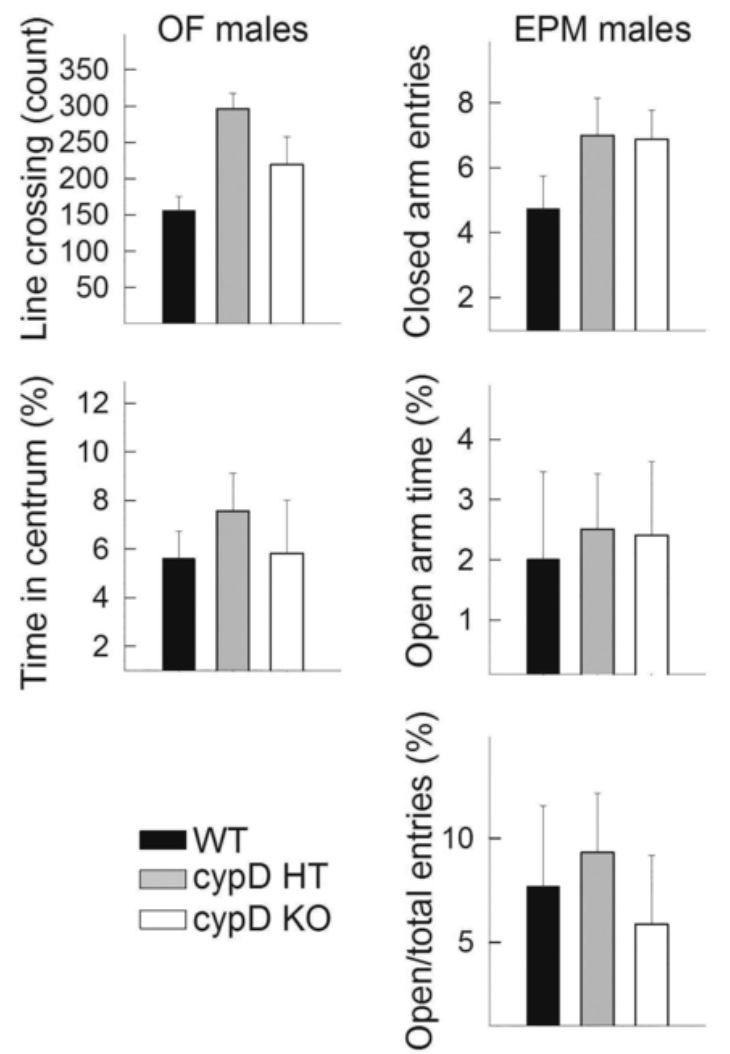
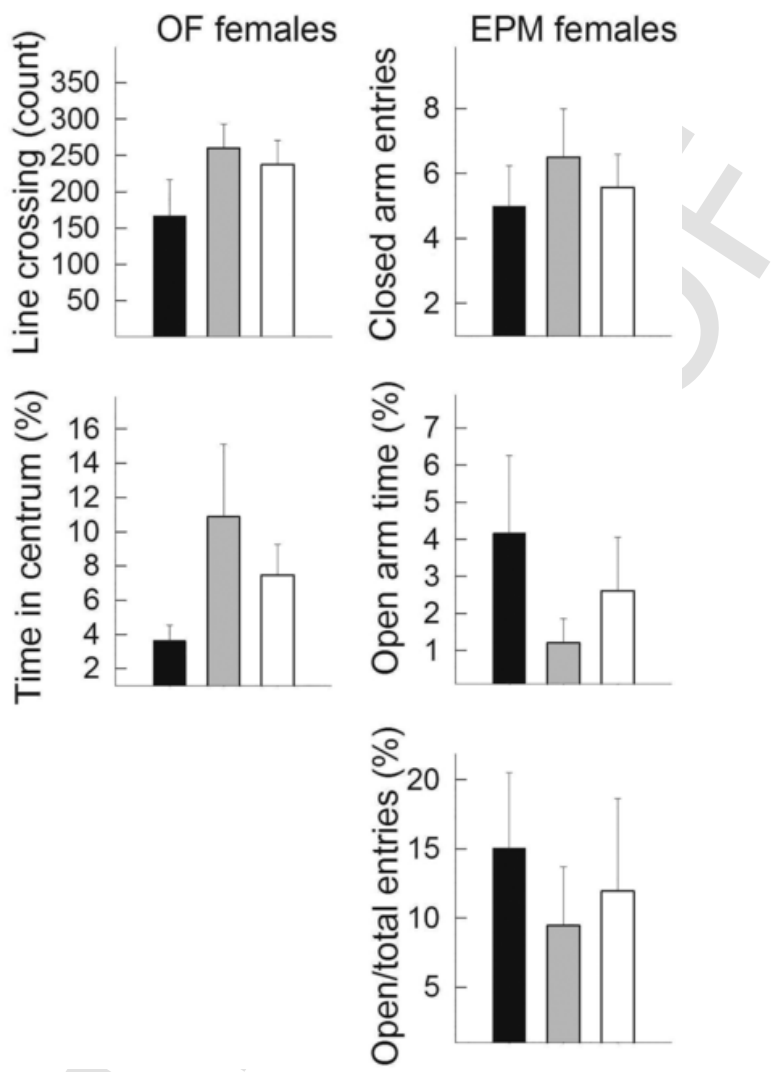

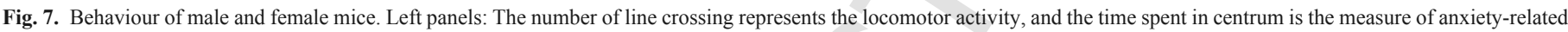

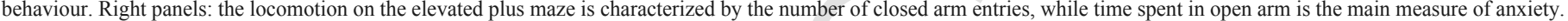
The open/total entries represent the locomotor-independent anxiety parameters. Data are averages from 10 mice per group.

As noted in Elrod et al. (2010)) Affymetrix gene array analysis revealed that 362 probe sets were significantly different (ANOVA, $\mathrm{p}<0.01$, with a minimum difference in gene expression of $25 \%$ between WT and cypD KO mice. A robust fluctuation in the expression of many genes is a commonly occurring problem with constitutive transgenic mice which are viable when homozygous. Conditional or inducible transgenic mice do not suffer from confounding chronic alterations in the expression of other genes, but such a mouse model could not have been used for aging studies. Thus, the evaluation of a moderate decrease in cypD (as in heterozygous mice) is a much better model for mimicking the effect of a drug inhibiting submaximally its target. Indeed, as shown in our results, it was the HT mice (both male and female) that exhibited a longer lifespan, compared to WT and KO cypD littermates. Relevant to this, treatment of Podospora anserina (a fungus suitable for aging studies) with low concentrations of cyclosporin A, also extended lifespan (Brust et al., 2010). As a word of caution though, male HT mice exhibited an early lethality compared to $\mathrm{KO}$ and WT mice, an observation that was not associated with gross pathological abnormalities, albeit the exact cause of the death was not estimated.

To evaluate whether this extension of lifespan is accompanied with changes in the quality of life in mice, we further examined the protein expression of aging markers and the behaviour of mice in an open-field and elevated plus maze test.

Regarding our approach to examine the expression of 15 (plus $\beta$-actin and GAPDH) proteins by Western blotting, instead of evaluating thousands of genes using RNA-quantitating methods as performed in Lu et al. (2004), Jiang et al. (2001) and Lee et al. (2000), or perhaps using even more recently advanced technologies such RNA-Seq V2 (Bottomly et al., 2011), it cannot be overemphasized that changes in mRNA do not necessarily reflect changes in protein expression (Tian et al., 2004; Vogel et al., 2010; Lundberg et al., 2010; Schwanhausser et al., 2011). A novel methodology that quantitates the abundance of hundreds if not thousands of different proteins in biological samples termed Reverse Phase Protein Array (RPPA) is becoming increasingly popular (Gallagher and Espina, 2014), however it still requires the extensive validation of the antibodies used. In our case, not more than four antibodies have been verified to be suitable for RPPA protocols (i.e., that of the RPPA Core facility of the MD Anderson Cancer Center) for the intended proteins. Finally, we have used immunohistochemical techniques to quantitate the regional expression of selected aging markers (GFAP, mGluR1 and $\alpha$-synuclein) in hippocampal, cortical and thalamic regions of the mouse brain, yielding information that are otherwise lost by homogenization procedures commonly employed prior to Western blotting. The results on protein expression of aging markers in the mouse forebrain as a function of gender and cypD and how do these compare to the study of $\mathrm{Lu}$ et al. (2004) regarding mRNA levels are shown in Table 2. Eight out of the 15 examined aging markers exhibited a statistically significant difference among some mice groups. This strongly attests to the notion that cypD regulates the expression of aging markers in the murine brain. Nevertheless, for the remaining of comparisons, the partial or complete deletion of cypD was not associated with abolition of the change of the aging marker as defined by Lu et al. (2004). For example, in $\mathrm{Lu}$ et al. there was an $\sim 2$ fold change in the total RNA coding for calbindin, calcineurin, HIF1- $\alpha$ and leptin receptor, while in our study there were no changes in the expression of these proteins for any comparisons. This reflects at least two facts: i) in $\mathrm{Lu}$ et al., comparisons were made in samples from human brain, while we compared those from transgenic mice, and ii) $\mathrm{Lu}$ et al. ex- 
amined total RNA levels, which does not necessarily translate to a difference in protein expression. By evaluating further the regional protein expression of GFAP, mGluR1 and $\alpha$-synuclein in the cortical, hippocampal and thalamic regions, it is striking that the partial disruption of the cypD gene led to upregulation of GFAP, while the complete disruption of cypD led to a decrease in GFAP expression. However, it is must be emphasized that GFAP - and the 'astrocytic response' in general- has been a recurrent theme of investigation regarding aging and associated maladies throughout the past two decades (Laping et al., 1994; Baba et al., 1997; Finch, 2003; Middeldorp and Hol, 2011; Chisholm and Sohrabji, 2016).

The results obtained from the elevated plus maze and the open-field test revealed no statistically significant differences among any groups. Although this may be at odds with the results in males shown in Luvisetto et al. (2008), there the mice were not as aged as in the present study. Thus, we can conclude that in aged mice the anxiogenic role of cypD deletion disappeared. Relevant to this, previous studies showed that aging might influence anxiety behaviour measured in open-field and elevated plus maze test (Botton et al., 2016; Shoji et al., 2016). There, it was shown that aging attenuated anxiety in the elevated plus maze, test but also induced hypolocomotion and anxiety in open-field.

\subsection{Conclusions}

The most important finding of the present study is that heterozygous mice exhibited longer lifespan than both cypD KO and WT mice. This suggests that regarding lifespan, a chronic, mild inhibition of cyclophilin D may be more beneficial than its complete absence. On the other hand, it is important to consider the findings by the group of Molkentin, where cypD-deficient mice developed pre-existing cardiac conditions, being more prone to metabolic heart failure (Elrod et al., 2010); in heart failure patients, this would translate to a probable inapplicability of chronic use of a cyclophilin D inhibitor. Thus, in subjects with compromised heart functions, the potential benefits of a chronic-mild inhibition of cypD on longevity could be outweighed by an increased risk of aggravating a looming or co-existing cardiac disease.

It is noteworthy, that there was an early mortality observed only in HT male mice. We have not sought the reasons for this phenomenon, which was statistically significant. Perhaps it is also associated with the increased longevity of the remaining mice, implying that those that could survive the diminished expression of cypD during their early life, acquire lifespan-increasing mechanisms, a scheme that operates only in males.

Finally, the amount of cypD expression appears to exert a complex effect on the expression of other proteins in the brains of aged male and female mice. Despite the fact that, a 'clear-cut' picture did not emerge from the findings presented above that could allow for a generalized conclusion, it is interesting that there were gender-dependent alterations: for only male mice, GAPDH, ATP6V1H, PKC- $\gamma$ and synapsin, while for only female mice, MEK4 and mGluR1 were altered. Only for cdk5, GFAP and sortilin changes were observed in mice of either gender. In most cases the levels were lower either only in $\mathrm{KO}$ or both in $\mathrm{HT}$ and $\mathrm{KO}$ animals. Only in male $\mathrm{KO}, \mathrm{PKC}-\gamma$ and synapsin showed elevations in protein expression, which were not detected in HT or any other female group. By investigating the regional expression differences of GFAP, mGluR1 and $\alpha$-synuclein, we also report that the partial expression of cypD upregulates GFAP, as opposed to downregulation of GFAP if cypD is not expressed, in aged mice. The biological relevance of cypD-induced alterations in GFAP, mGluR1 and $\alpha$-synuclein expression may lie in glial response or astrogliosis and synaptic transmission, concepts that are inherently in- volved in cognitive functions as well as pathophysiologic homeostasis of the brain.

\section{Materials and methods}

\subsection{Animals}

Genetically modified mice originating from the C57B16/J strain, which were heterozygous for the gene encoding cypD were obtained from the Dana-Faber Cancer Institute and mated with C57B16/F mice in our facilities. To ensure a homologous genetic background, the resulting mice were backcrossed with $\mathrm{C} 57 \mathrm{~B} 16 / \mathrm{J}$ mice for at least eight generations. Mice were housed in a room maintained at $20-22{ }^{\circ} \mathrm{C}$ on a 12-hour light-dark cycle with food and water available ad libitum. All experimental procedures were performed according to the Animal Care and Use Committee (Egyetemi Állatkísérleti Bizottság) guidelines and the regulations set by the European Communities Council Directive (2010/63/EU). Mice were categorized in the following six groups (all aged $>24$ months): males, wild-type (WT); males, cypD +/- (HT); males cypD -/- (KO); females, WT; females, (HT); and females, $(\mathrm{KO})$.

\subsection{Tissue preparation}

\subsubsection{Tissue preparation for Western blotting}

Mice were killed by cervical dislocation. Subsequently, the forebrain was carefully taken out as a whole, chopped with scissors and washed several times with PBS. Then, brain fragments were homogenized in a PBS solution containing $20 \mathrm{mM}$ lauryl-maltoside and a protease inhibitor cocktail (Calbiochem, Protease Inhibitor Cocktail Set IV, product number 539136). The processes of brain harvesting and homogenization took place at $4{ }^{\circ} \mathrm{C}$. Afterwards, the samples were kept on ice for $30 \mathrm{~min}$; subsequently, they were centrifuged at $3000 \mathrm{rpm}$ for $3 \mathrm{~min}$, and the supernatants were collected, snap-frozen and stored at $-20{ }^{\circ} \mathrm{C}$ till further use.

\subsubsection{Tissue preparation for immunohistochemistry}

Animals were anesthetized with chloral hydrate (Reanal Private Ltd., Budapest, Hungary) and transcardially perfused with $4 \%$ paraformaldehyde (Merck, Darmstadt, Germany) containing 2.5\% acrolein (Merck) in $100 \mathrm{mM} \mathrm{KH}_{2} \mathrm{PO}_{4}, \mathrm{pH}$ 6.8. Whole brains were removed from the skulls and post-fixed in $4 \%$ paraformaldehyde for $24 \mathrm{~h}$. Coronal blocks were cut so that they contained the entire hippocampi of both hemispheres (between Bregma $-0.82 \mathrm{~mm}$ and $-3.80 \mathrm{~mm}$ ); the blocks were subsequently immersed into $30 \%$ sucrose. Once the blocks sunk to the bottom of the containers, they were further cut on a sliding microtome. The coronal sections were cut at a $30 \mu \mathrm{m}$ thickness and collected one-by-one in 96 well plates. The sections were kept in a cryoprotectant antifreeze solution (Watson et al., 1986) at $-20^{\circ} \mathrm{C}$ until further use.

\subsection{Immunohistochemistry}

For single immunocytochemistry of the free floating sections, the antigen-antibody complex was visualized by conventional Nickel intensified DAB reaction product as described previously (Vereczki et al., 2006). For fluorescence single, double and triple immunocytochemistry the sections were processed by $\mathrm{ABC}$ ( $\mathrm{ABC}$ Elite Kits, Vector Laboratories, Burlingame, $\mathrm{CA}$ ) and biotin amplification as described previously (Berghorn et al., 1994). The antibodies used were as follows: rabbit anti-mGluR1a (a generous gift of Dr. Shigemoto), dilution for Ni-DAB at 1:30,000, and for biotin amplification fluorescence staining at 1:15,000; mouse anti-GFAP antibody at 1:50,000 (Abcam, Cambridge, UK); mouse anti-NeuN (Chemicon Interna- 
tional, Temecula, CA) at 1:7000 for fluorescence staining; mouse anti-GFAP-Cy3 conjugated antibody (Sigma-Aldrich) at 1:50,000 and anti- $\alpha$ synuclein at 1:50,000 (Abcam).

\subsection{Quantification of immunohistochemical results}

The sections were evaluated by using quantitative sampling approach with a random starting point; 5 sections from the brain of each animal were selected that were equally distant from each other. For GFAP, cells were counted, and for mGLuR1 and $\alpha$-synuclein, particles were counted. Counting occurred using ImageJ. Regarding mGLuR 1 and $\alpha$-synuclein, by using a tool of the ImageJ software we could set the size of the particles to be counted; thus we used identical sets for each section from the different groups (WT, HT, KO) in order to avoid a subjective bias and perform un-biased statistical comparisons. For GFAP, by using ImageJ we counted the number of GFAP-positive stained cells in each section. Statistical significance was determined comparing the 3 groups (WT, HT, KO) by ANOVA on Ranks followed by one-way ANOVA and Tukey's test post-hoc analysis. Data with $\mathrm{p}<0.05$ were considered significant.

\subsection{Western blotting}

Frozen pellets were thawed on ice, their protein concentration was determined using the bicinchoninic acid assay and separated by sodium dodecyl sulfate - polyacrylamide gel electrophoresis (SDS-PAGE). Separated proteins were transferred to a methanol-activated polyvinylidene difluoride membrane. Immunoblotting was performed as recommended by the manufacturers of the antibodies. The antibodies used and their titers are shown in Table 1. Immunoreactivity was detected using the appropriate peroxidase-linked secondary antibody (1:5000, donkey anti-rabbit or donkey anti-mouse, Jackson Immunochemicals Europe Ltd., Cambridgeshire, UK) and enhanced chemiluminescence detection reagent (ECL system; Amersham Biosciences GE Healthcare Europe GmbH, Vienna, Austria). Densitometric analysis of the bands was performed in Fiji (Schindelin et al., 2012). We have also ratioed the densitometric signal of each band to that obtained using $\beta$-actin (for the corresponding mouse brain sample), however, this has yielded the exact same information regarding statistical comparisons; this is probably due to the lack of variability of $\beta$-actin expression among mice and genotypes. Thus, bar-graphs representing densitometric analyses of band intensities are given by assigning an O.D. of 1 for the averaged bands obtained from WT mice.

\subsection{Behavioural tests}

The tests were videotaped and analysed later by an experimenter blind to the treatments by means of a computer-based event recorder (H77, Budapest, Hungary). Behavioural parameters are expressed as average \pm SEM for all groups; data were analysed by using two-way ANOVA (factors: gender and genotypes). As there was no interaction between the main factors, post hoc analysis was not conducted.

\subsubsection{Open field test}

The open field (OF) was a white non-transparent plastic box of $45 \times 45 \times 25 \mathrm{~cm}$ (height). Subjects were placed in one corner of the $\mathrm{OF}$ and were allowed to explore it for $5 \mathrm{~min}$. The apparatus was covered with a transparent Plexiglas lid during testing and was cleaned with tap water and a paper towel between subjects. Locomotor activity was scored by counting the crossings of the lines that divided the open field into 16 equal squares. The grid was drawn on the video screen; thus, it was invisible to the subjects. Exploration in the central area (i.e. the 4 squares in the center of the apparatus) was also scored as a measure of anxiety-like behaviour.

\subsubsection{Elevated plus maze}

The Elevated plus maze (EPM) was made of black-painted aluminium. It consisted of two open arms $(30 \times 7 \mathrm{~cm})$ and two closed arms $(30 \times 7 \mathrm{~cm}$ with $30 \mathrm{~cm}$ high walls $)$ that were connected by a central platform $(7 \times 7 \mathrm{~cm})$. The plus maze was elevated to $70 \mathrm{~cm}$ from the floor. Each mouse was transferred in the home-cage from the housing room to the test room and was immediately placed on the central platform of the EPM, with the head facing one of the open arms. The apparatus was cleaned with tap water and a paper towel between tests. EPM exposure lasted $5 \mathrm{~min}$. The percentage of time spent in open arms and open/total (open plus closed) arm entries ratio (an entry was defined as having three paws of animal in a defined compartment) were calculated and used as measures of anxiety-like behaviour. The number of closed arm entries was used to estimate the general locomotor activity of the animal.

\subsection{Statistics}

For behavioural parameters average \pm SEM were given for all groups and the data were analysed by using two-way ANOVA (factors: gender and genotypes). As there was no interaction between the main factors, post hoc analysis was not conducted. For Western blotting and IHC, mean sample value and standard deviation was calculated using the 5 samples of each group, and 4 samples for IHC slide, respectively. Western blotting experiments were done in duplicates if there were no differences among mice groups, or triplicates, if there were differences observed. Statistical significance was determined comparing the 3 groups (WT, HT, KO) by ANOVA on Ranks followed by one-way ANOVA and Tukey's test post-hoc analysis. Data with $\mathrm{p}<0.05$ were considered significant. Graphs are plotted as means with bars representing the standard error of the groups. Survival rates were analysed using a Kaplan-Meier survival analysis and post-hoc with a Holm-Sidak test for pairwise multiple comparison.

\section{Disclosure statement}

None of the authors have conflict of interest or disclosures relevant to this manuscript.

\section{Acknowledgements}

This work was supported by the Országos Tudományos Kutatási Alapprogram (OTKA) [grant 112230], the Hungarian Academy of Sciences [grant 02001], the Hungarian Brain Research Program [KTIA_13_NAP-A-III/6] to V. A.-V., and MTA-SE Lendület Neurobiochemistry Research Division [grant 95003], OTKA NNF [grant 78905], OTKA NNF2 [grant 85658], OTKA K [grant 100918] and Egészségügyi Tudományos Tanács [grant 55160] to C. C.

\section{References}

Azzolin, L., von Stockum, S., Basso, E., Petronilli, V., Forte, M.A., Bernardi, P., 2010 The mitochondrial permeability transition from yeast to mammals. FEBS Lett. 584, 2504-2509.

Baba, H., Nakahira, K., Morita, N., Tanaka, F., Akita, H., Ikenaka, K., 1997. GFAP gene expression during development of astrocyte. Dev. Neurosci. 19, 49-57.

Baines, C.P., Kaiser, R.A., Purcell, N.H., Blair, N.S., Osinska, H., Hambleton, M.A., Brunskill, E.W., Sayen, M.R., Gottlieb, R.A., Dorn, G.W., Robbins, J., Molkentin, J.D., 2005. Loss of cyclophilin D reveals a critical role for mitochondrial permeability transition in cell death. Nature 434, 658-662.

Barsukova, A., Komarov, A., Hajnoczky, G., Bernardi, P., Bourdette, D., Forte, M., 2011. Activation of the mitochondrial permeability transition pore modulates $\mathrm{Ca}^{2+}$ responses to physiological stimuli in adult neurons. Eur. J. Neurosci. 33, 831-842. 
Basso, E., Fante, L., Fowlkes, J., Petronilli, V., Forte, M.A., Bernardi, P., 2005. Properties of the permeability transition pore in mitochondria devoid of cyclophilin D. J. Biol. Chem. 280, 18558-18561.

Berchtold, N.C., Cribbs, D.H., Coleman, P.D., Rogers, J., Head, E., Kim, R., Beach, T., Miller, C., Troncoso, J., Trojanowski, J.Q., Zielke, H.R., Cotman, C.W., 2008. Gene expression changes in the course of normal brain aging are sexually dimorphic. Proc. Natl. Acad. Sci. U. S. A. 105, 15605-15610.

Berghorn, K.A., Bonnett, J.H., Hoffman, G.E., 1994. cFos immunoreactivity is enhanced with biotin amplification. J. Histochem. Cytochem. 42, 1635-1642.

Bernardi, P., Di, L.F., Fogolari, F., Lippe, G., 2015. From ATP to PTP and back: a dual function for the mitochondrial ATP synthase. Circ. Res. 116, 1850-1862.

Bernardi, P., Rasola, A., Forte, M., Lippe, G., 2015. The mitochondrial permeability transition pore: channel formation by F-ATP synthase, integration in signal transduction, and role in pathophysiology. Physiol. Rev. 95, 1111-1155.

Bonora, M., Wieckowski, M.R., Chinopoulos, C., Kepp, O., Kroemer, G., Galluzzi, L., Pinton, P., 2015. Molecular mechanisms of cell death: central implication of ATP synthase in mitochondrial permeability transition. Oncogene 34, 1475-1486.

Bottomly, D., Walter, N.A., Hunter, J.E., Darakjian, P., Kawane, S., Buck, K.J., Searles, R.P., Mooney, M., McWeeney, S.K., Hitzemann, R., 2011. Evaluating gene expression in $\mathrm{C} 57 \mathrm{BL} / 6 \mathrm{~J}$ and DBA/2J mouse striatum using RNA-seq and microarrays. PLoS ONE 6, e17820.

Botton, P.H., Pochmann, D., Rocha, A.S., Nunes, F., Almeida, A.S., Marques, D.M., Porciuncula, L.O., 2016. Aged mice receiving caffeine since adulthood show distinct patterns of anxiety-related behavior. Physiol. Behav. 170, 47-53.

Brust, D., Daum, B., Breunig, C., Hamann, A., Kuhlbrandt, W., Osiewacz, H.D., 2010 Cyclophilin D links programmed cell death and organismal aging in Podospora anserina. Aging Cell 9, 761-775.

Chisholm, N.C., Sohrabji, F., 2016. Astrocytic response to cerebral ischemia is influenced by sex differences and impaired by aging. Neurobiol. Dis. 85, 245-253.

Crompton, M., 2004. Mitochondria and aging: a role for the permeability transition? Aging Cell 3, 3-6.

Davis, T.L., Walker, J.R., Campagna-Slater, V., Finerty, P.J., Paramanathan, R., Bernstein, G., MacKenzie, F., Tempel, W., Ouyang, H., Lee, W.H., Eisenmesser, E.Z., Dhe-Paganon, S., 2010. Structural and biochemical characterization of the human cyclophilin family of peptidyl-prolyl isomerases. PLoS Biol. 8, e1000439.

Du, H., Guo, L., Fang, F., Chen, D., Sosunov, A.A., McKhann, G.M., Yan, Y., Wang, C., Zhang, H., Molkentin, J.D., Gunn-Moore, F.J., Vonsattel, J.P., Arancio, O., Chen, J.X., Yan, S.D., 2008. Cyclophilin D deficiency attenuates mitochondrial and neuronal perturbation and ameliorates learning and memory in Alzheimer's disease. Nat. Med. 14, 1097-1105.

Du, H., Guo, L., Zhang, W., Rydzewska, M., Yan, S., 2011. Cyclophilin D deficiency improves mitochondrial function and learning/memory in aging Alzheimer diseas mouse model. Neurobiol. Aging 32, 398-406.

Eliseev, R.A., Filippov, G., Velos, J., VanWinkle, B., Goldman, A., Rosier, R.N., Gunter, T.E., 2007. Role of cyclophilin D in the resistance of brain mitochondria to the permeability transition. Neurobiol. Aging 28, 1532-1542.

Elrod, J.W., Molkentin, J.D., 2013. Physiologic functions of cyclophilin D and the mitochondrial permeability transition pore. Circ. J. 77, 1111-1122.

Elrod, J.W., Wong, R., Mishra, S., Vagnozzi, R.J., Sakthievel, B., Goonasekera, S.A., Karch, J., Gabel, S., Farber, J., Force, T., Brown, J.H., Murphy, E., Molkentin, J.D., 2010. Cyclophilin D controls mitochondrial pore-dependent $\mathrm{Ca}(2+)$ exchange, metabolic flexibility, and propensity for heart failure in mice. J. Clin. Invest. $120,3680-3687$.

Finch, C.E., 2003. Neurons, glia, and plasticity in normal brain aging. Neurobiol. Aging 24 (Suppl. 1), S123-S127.

Gallagher, R.I., Espina, V., 2014. Reverse phase protein arrays: mapping the path towards personalized medicine. Mol. Diagn. Ther. 18, 619-630.

Gonzalez-Freire, M., de Cabo, R., Bernier, M., Sollott, S.J., Fabbri, E., Navas, P., Ferrucci, L., 2015. Reconsidering the role of mitochondria in aging. J. Gerontol. A Biol. Sci. Med. Sci. 70, 1334-1342.

Halestrap, A.P., Davidson, A.M., 1990. Inhibition of Ca2(+)-induced large-amplitude swelling of liver and heart mitochondria by cyclosporin is probably caused by the inhibitor binding to mitochondrial-matrix peptidyl-prolyl cis-trans isomerase and preventing it interacting with the adenine nucleotide translocase. Biochem. J. 268, 153-160.

Izzo, V., Bravo-San Pedro, J.M., Sica, V., Kroemer, G., Galluzzi, L., 2016. Mitochondrial permeability transition: new findings and persisting uncertainties. Trends Cell Biol. 26, 655-667.

Jiang, C.H., Tsien, J.Z., Schultz, P.G., Hu, Y., 2001. The effects of aging on gene expression in the hypothalamus and cortex of mice. Proc. Natl. Acad. Sci. U. S. A. $98,1930-1934$.

Johnson, N., Khan, A., Virji, S., Ward, J.M., Crompton, M., 1999. Import and processing of heart mitochondrial cyclophilin D. Eur. J. Biochem. 263, 353-359.

Korge, P., Yang, L., Yang, J.H., Wang, Y., Qu, Z., Weiss, J.N., 2011. Protective role of transient pore openings in calcium handling by cardiac mitochondria. J. Biol. Chem. 286, 34851-34857.

Laker, R.C., Taddeo, E.P., Akhtar, Y.N., Zhang, M., Hoehn, K.L., Yan, Z., 2016. The mitochondrial permeability transition pore regulator cyclophilin D exhibits tissue-specific control of metabolic homeostasis. PLoS One 11, e0167910.
Lane, R.K., Hilsabeck, T., Rea, S.L., 2015. The role of mitochondrial dysfunction in age-related diseases. Biochim. Biophys. Acta 1847, 1387-1400.

Laping, N.J., Teter, B., Nichols, N.R., Rozovsky, I., Finch, C.E., 1994. Glial fibrillary acidic protein: regulation by hormones, cytokines, and growth factors. Brain Pathol. 4, 259-275.

Lee, C.K., Weindruch, R., Prolla, T.A., 2000. Gene-expression profile of the ageing brain in mice. Nat. Genet. 25, 294-297.

Lu, T., Pan, Y., Kao, S.Y., Li, C., Kohane, I., Chan, J., Yankner, B.A., 2004. Gene regulation and DNA damage in the ageing human brain. Nature 429, 883-891.

Lundberg, E., Fagerberg, L., Klevebring, D., Matic, I., Geiger, T., Cox, J., Algenas, C., Lundeberg, J., Mann, M., Uhlen, M., 2010. Defining the transcriptome and proteome in three functionally different human cell lines. Mol. Syst. Biol. 6, 450.

Luvisetto, S., Basso, E., Petronilli, V., Bernardi, P., Forte, M., 2008. Enhancement of anxiety, facilitation of avoidance behavior, and occurrence of adult-onset obesity in mice lacking mitochondrial cyclophilin D. Neuroscience 155, 585-596.

Martin, L.J., Semenkow, S., Hanaford, A., Wong, M., 2014. Mitochondrial permeability transition pore regulates Parkinson's disease development in mutant alpha-synuclein transgenic mice. Neurobiol. Aging 35, 1132-1152.

Middeldorp, J., Hol, E.M., 2011. GFAP in health and disease. Prog. Neurobiol. 93, 421-443.

Nakagawa, T., Shimizu, S., Watanabe, T., Yamaguchi, O., Otsu, K., Yamagata, H., Inohara, H., Kubo, T., Tsujimoto, Y., 2005. Cyclophilin D-dependent mitochondrial permeability transition regulates some necrotic but not apoptotic cell death. Nature 434, 652-658.

Payne, B.A., Chinnery, P.F., 2015. Mitochondrial dysfunction in aging: much progress but many unresolved questions. Biochim. Biophys. Acta 1847, 1347-1353.

Piot, C., Croisille, P., Staat, P., Thibault, H., Rioufol, G., Mewton, N., Elbelghiti, R., Cung, T.T., Bonnefoy, E., Angoulvant, D., Macia, C., Raczka, F., Sportouch, C., Gahide, G., Finet, G., Andre-Fouet, X., Revel, D., Kirkorian, G., Monassier, J.P., Derumeaux, G., Ovize, M., 2008. Effect of cyclosporine on reperfusion injury in acute myocardial infarction. N. Engl. J. Med. 359, 473-481.

Schindelin, J., Arganda-Carreras, I., Frise, E., Kaynig, V., Longair, M., Pietzsch, T., Preibisch, S., Rueden, C., Saalfeld, S., Schmid, B., Tinevez, J.Y., White, D.J., Hartenstein, V., Eliceiri, K., Tomancak, P., Cardona, A., 2012. Fiji: an open-source platform for biological-image analysis. Nat. Methods 9, 676-682.

Schinzel, A.C., Takeuchi, O., Huang, Z., Fisher, J.K., Zhou, Z., Rubens, J., Hetz, C., Danial, N.N., Moskowitz, M.A., Korsmeyer, S.J., 2005. Cyclophilin D is a component of mitochondrial permeability transition and mediates neuronal cell death after focal cerebral ischemia. Proc. Natl. Acad. Sci. U. S. A. 102, 12005-12010.

Schwanhausser, B., Busse, D., Li, N., Dittmar, G., Schuchhardt, J., Wolf, J., Chen, W., Selbach, M., 2011. Global quantification of mammalian gene expression control. Nature 473, 337-342.

Shoji, H., Takao, K., Hattori, S., Miyakawa, T., 2016. Age-related changes in behavior in C57BL/6J mice from young adulthood to middle age. Mol. Brain 9, 11.

Tian, Q., Stepaniants, S.B., Mao, M., Weng, L., Feetham, M.C., Doyle, M.J., Yi, E.C., Dai, H., Thorsson, V., Eng, J., Goodlett, D., Berger, J.P., Gunter, B., Linseley, P.S., Stoughton, R.B., Aebersold, R., Collins, S.J., Hanlon, W.A., Hood, L.E., 2004. Integrated genomic and proteomic analyses of gene expression in mammalian cells. Mol. Cell. Proteomics 3, 960-969.

Toman, J., Fiskum, G., 2011. Influence of aging on membrane permeability transition in brain mitochondria. J. Bioenerg. Biomembr. 43, 3-10.

Vereczki, V., Martin, E., Rosenthal, R.E., Hof, P.R., Hoffman, G.E., Fiskum, G., 2006. Normoxic resuscitation after cardiac arrest protects against hippocampal oxidative stress, metabolic dysfunction, and neuronal death. J. Cereb. Blood Flow Metab. 26, 821-835.

Vogel, C., Abreu, R.S., Ko, D., Le, S.Y., Shapiro, B.A., Burns, S.C., Sandhu, D., Boutz, D.R., Marcotte, E.M., Penalva, L.O., 2010. Sequence signatures and mRNA concentration can explain two-thirds of protein abundance variation in a human cell line. Mol. Syst. Biol. 6, 400.

Waldmeier, P.C., Zimmermann, K., Qian, T., Tintelnot-Blomley, M., Lemasters, J.J., 2003. Cyclophilin D as a drug target. Curr. Med. Chem. 10, 1485-1506.

Wang, Y., Hekimi, S., 2015. Mitochondrial dysfunction and longevity in animals: untangling the knot. Science 350, 1204-1207.

Wang, X., Carlsson, Y., Basso, E., Zhu, C., Rousset, C.I., Rasola, A., Johansson, B.R., Blomgren, K., Mallard, C., Bernardi, P., Forte, M.A., Hagberg, H., 2009. Developmental shift of cyclophilin D contribution to hypoxic-ischemic brain injury. J. Neurosci. 29, 2588-2596.

Watson Jr., R.E., Wiegand, S.J., Clough, R.W., Hoffman, G.E., 1986. Use of cryoprotectant to maintain long-term peptide immunoreactivity and tissue morphology. Peptides 7, 155-159.

Yin, F., Sancheti, H., Liu, Z., Cadenas, E., 2016. Mitochondrial function in ageing: coordination with signalling and transcriptional pathways. J. Physiol. 594, 2025-2042.

Ziegler, D.V., Wiley, C.D., Velarde, M.C., 2015. Mitochondrial effectors of cellular senescence: beyond the free radical theory of aging. Aging Cell 14, 1-7. 